Iranian Journal of Pathology | ISSN: 2345-3656

\title{
Plasma Fibrinogen and D-dimer in Children With Sepsis: A Single-center Experience
}

\author{
Abhimanyu Sharma ${ }^{1}$, Meera Sikka ${ }^{1 *}$, Sunil Gomber ${ }^{2}$, Satendra Sharma $^{1}$ \\ 1. Dept. of Pathology, University College of Medical Sciences, Delhi, India \\ 2. Dept. of Pediatrics, University College of Medical Sciences, Delhi, India
}

\begin{tabular}{c}
\hline KEYWORDS \\
\hline child; \\
Sepsis; \\
Disseminated Intravascular Co- \\
agulation (DIC); \\
India \\
\hline
\end{tabular}

\section{Article Info}

Received 28 Dec 2017;

Accepted 05 April 2018;

Published Online 17 July 2018;

\begin{abstract}
Background \& objective: In sepsis, enhanced fibrin formation, impaired fibrin degradation, and intravascular fibrin deposition lead to a prothrombotic state. The current study aimed at measuring various coagulation parameters to predict an early marker for disseminated intravascular coagulation(DIC).
\end{abstract}

Methods: The current prospective study was conducted from January 2012 to April 2013 on 50 children aged 1-10 years with clinically suspected sepsis referred to the Department of Pediatrics of a tertiary care center in New Delhi, India. Patients were evaluated in accordance with criteria for acute infection (ie, symptoms less than seven days) confirmed in all patients in the laboratory. Patients receiving antibiotics 24-48 hours preceding admission were excluded from the study. Prothrombin time, activated partial thromboplastin time, plasma fibrinogen, and D-dimer were measured at the time of admission in 50 patients and 50 controls.

Results \& Conclusion: D-dimer was positive in 36 (72\%) patients and negative in all controls. The difference was statistically significant $(P<0.01)$. Plasma fibrinogen was significantly $(P<0.01)$ higher in patients compared with the controls. It was decreased in $6 \%$ and increased in $8 \%$ of the patients, and normal in all controls.PT and APTT were significantly $(P<0.01)$ higher in patients compared with the controls.

Though none of the current study patients developed overt disseminated intravascular coagulation, the high positivity for D-dimer suggested that it should be measured in children with sepsis for early identification of DIC. This can aid better management as additional coagulation based therapy such as recombinant anti-thrombin and thrombomodulin may help to improve prognosis.

Corresponding information:

Meera Sikka, Dept. of Pathology, University College of Medical Sciences, Delhi, India.

E-mail:meerasikka55@gmail.com

Copyright (C) 2018, IRANIAN JOURNAL OF PATHOLOGY. This is an open-access article distributed under the terms of the Creative Commons Attribution-noncommercial 4.0 International License which permits copy and redistribute the material just in noncommercial usages, provided the original work is properly cited.

\section{Introduction}

Sepsis is defined as the presence of an infection proven/suspected in a patient with systemic inflammatory response syndrome(SIRS). (1) The manifestations of SIRS include two or more of the following: temperature $>38^{\circ} \mathrm{C}$ or $<36^{\circ} \mathrm{C}$, heart rate $>90 /$ minute, respiratory rate $>20 /$ minute along with a total leucocyte count $>12 \times 10^{9} / \mathrm{L}$ or $>10 \%$ immature band forms (2). These are modified in children (1). Sepsis remains the most common cause of death in infants and children worldwide and also in India $(2,3)$. Acute inflammation activates the coagulation system result- ing in widespread intravascular deposition of fibrin. Impaired fibrinolysis evident by increased levels of plasminogen activator inhibitor-1 further contributes to the presence of fibrin. There is simultaneous depression of natural anticoagulants such as Protein $\mathrm{C}$ and Protein S (2). In sepsis, enhanced fibrin formation, impaired fibrin degradation, and intravascular fibrin deposition lead to a prothrombotic state (4). Fibrin (fibrinogen)-degradation products (FDPs) are protein fragments of various sizes that result from the proteolytic action of plasmin on fibrin or fibrinogen. Plasma levels of these fragments are commonly in- 
creased in association with disseminated intravascular coagulation (DIC) and fibrinogenolysis, disorders in which their presence is of considerable diagnostic significance (5).

D-dimer, formed on cleavage of cross linked fibrin is a specific marker of fibrinolysis.It is identified in the blood of patients with various thrombotic and thrombolytic disorders (6).It is reported that levels of D-dimer increase in patients with sepsis due to fibrinolysis (7).Other causes of increased D-dimer include venous thromboembolism, syncope, heart failure, trauma, and cancer (8).D-dimer is more specific compared to FDP, which is more sensitive to detect DIC (9).

While activation of coagulation depletes platelets and coagulation factors contributing to clinical bleeding, formation of micro-thrombi causes organ dysfunction (10). DIC remains an independent predictor of organ failure and death in patients with sepsis (11).

\section{Materials and Methods}

\section{Subjects}

A prospective pilot study was conducted from January 2012 to April 2013 on 50 children aged 1-10 years with clinically suspected acute infection and manifestations of SIRS referred to the Department of Pediatrics of a tertiary care center in New Delhi, India. Patients were evaluated in accordance with criteria for acute infection (ie, symptoms for less than seven days) confirmed in all patients in the laboratory. Patients receiving antibiotics $24-48$ hours preceding the admission were excluded from the study. Only 10 patients had a confirmed infection based on blood/cerebrospinal fluid/ pleural fluid culture. Ten patients had radiological evidence of infection (chest X-ray showed features of pneumonia) and in 30 patients infection was diagnosed by elevated proteins $(100-500 \mathrm{mg} / \mathrm{dL})$ and reduced glucose $(<50 \mathrm{mg} / \mathrm{dL})$ based on biochemical examination of CSF. Fifty age matched, healthy controls without any clinical evidence of infection were also studied prospectively. Informed consent was taken from the parents/guardians of all children. The study protocol was approved by the Institutional Ethics Committee for human research.

\section{Materials and Methods}

Prothrombin time (PT) (Dade Behring Thromborel S), activated partial thromboplastin time (APTT) (Dade Behring Actin FS), plasma fibrinogen (Siemens based on Clauss technique), and D-dimer (Bioscientifica SA, semi-quantitative latex agglutination method) were measured at the time of admission in all patients and controls. All children were followed up for recovery/ DIC/ death for seven days.

\section{Statistical analysis}

Unpaired t-test was used to compare blood parameters between the cases and controls.Level of significance was 0.05 .

\section{Results \& Discussion}

The age of the patients (range 1-10 years, mean \pm standard deviation (SD) 6.4 \pm 2.7 ) and controls (range 1-10years, mean \pm SD $6.4 \pm 2.7$ ) was not significantly different. Each group comprised of 32 (64\%) males and $18(36 \%)$ females. Of the 10 cases positive based on culture (nine on blood culture, one on culture of pleural fluid), Staphylococcus aureus and Klebsiella pneumoniae were identified in six and four patients, respectively.

PT and APTT were significantly $(P<0.01)$ higher in patients compared with controls. Prolonged PT and APTT were observed in 9 (18\%) and 24 (48\%) patients, respectively. PT and APTT were normal in all the controls.

Plasma fibrinogen was significantly $(P<0.01)$ higher in patients compared with controls (mean \pm SD of $317.4 \pm 79.5 \mathrm{mg} / \mathrm{dL}$ ) (reference range: $150-400 \mathrm{mg} /$ dL). The difference was statistically significant. Plasma fibrinogen increased in eight (16\%) and decreased in three $(6 \%)$ patients; and was normal in all controls.

D-dimer was positive in $36(72 \%)$ patients and negative in all controls. The difference was statistically significant $(P<0.01)$.None of the patients had clinical manifestations of DIC such as petechial haemorrhages, purpura or bleeding from any sites.

On follow up for 7 days, five patients died and one had persistent organ dysfunction. The mortality in the 
current study was $10 \%$. Three $(60 \%)$ out of five dead patients had an elevated fibrinogen. D-dimer was positive in all $5(100 \%)$ expired patients.

Sepsis is the systemic inflammatory response to infection. The reported incidence of sepsis in India is 11-24.5/1000 live births (3). Worldwide, it remains the most common cause of death in infants and children (2). Hemostatic abnormalities including DIC and multiple organ dysfunction syndrome are major causes of mortality in such children (4).

In the current study, plasma fibrinogen and D-dimer were estimated in 50 children with sepsis. Plasma fibrinogen increased in eight (16\%) and decreased in three $(6 \%)$ patients. Increase in the level of fibrinogen in patients with sepsis has been observed by other authors $(7,12)$. Fibrinogen is an acute phase reactant and may be elevated in the early stages of sepsis. Kim et al, observed an increased plasma fibrinogen in $43.5 \%$ of patients and decreased fibrinogen in $23.5 \%$ adult patients with sepsis (13). Lower fibrinogen levels have also been reported in neonates with sepsis (12, 14). The reduced fibrinogen in patients with acute infection may possibly indicate activation of coagulation leading to its consumption.

D-dimer, a specific marker of fibrinolysis was positive in 36 out of $50(72 \%)$ patients. Elevated levels result from activation of coagulation. Kim et al, observed D-dimer positivity in $100 \%$ of patients with sepsis (13). Kinasewitz et al, also reported D-dimer positivity in $99.7 \%$ of patients with severe sepsis (15). In a study conducted on 47 patients with sepsis, 18 with severe sepsis and 17 with septic shock, D-dimer was detected in $49 \%$ of patients and was significantly higher than that of the controls (16). The positivity increased further in severe sepsis and septic shock. Peker et al., studied global fibrinolytic capacity in 61 newborn infants and found that D-dimer levels were significantly $(P<0.05)$ higher in patients compared with the controls (17).Hesselvik et al.studied 53 patients with severe infection; all of them showed positivity for D-dimer but none had overt DIC (7). The mortality in the current study was $10 \%$, while $72 \%$ of patients were positive for D-dimer;none of these patients had clinical manifestations of DIC.The high positivity for D-dimer suggested that it should be measured in children with sepsis for early identification of DIC. This aids better management since additional coagulation based therapy such as recombinant anti-thrombin and thrombomodulin may help to improve prognosis.

\section{Limitations}

Patients were followed up for seven days only, hence data beyond this period was not available.

\section{Informed consent}

Written informed consent was obtained from the parents/guardians of the patients included in the study.

\section{Conflict of interests}

The authors declared no conflict of interest.

\section{References}

1. Wynn J, Cornell TT, Wong HR, Shanley TP, Wheeler DS. The Host Response to Sepsis and Developmental Impact. Pediatrics. 2010;125(5):1031-41. https://doi. org/10.1542/peds.2009-3301 PMID:20421258 PMCID:PMC2894560

2. Short MA. Linking the sepsis triad of inflammation, coagulation and suppressed fibrinolysis to infants. Adv Neonatal Care. 2004;4(5):25873. PMID: 15517521

3. Mumbai Mirror Bureau. Sepsis kills more than cancer, AIDS put together: study. Mumbai mirror 2012 Sep 12. City (col. 2)

4. Semeraro N, Ammollo CT, Semeraro F, Colucci M. Sepsis, thrombosis and organ dysfunction. Thromb Res. 2012;129(3):290-5. https://doi.org/10.1016/j.thromres.2011.10.013 PMID:22061311

5. Rodgers GM, Lehman CM. Diagnostic Approach to the Bleeding Disorders. In: Wintrobe's Clinical Hematology. 13nd ed. Philadelphia: Lippincott Williams and Wilkins;2013. p. $2419-50$

6. Moresco RN, Vargas LC, Voegeli CF, Santos RC. D-dimer and its relationship to fibrinogen/fibrin degradation products (FDPs) in disorders associated with activation of co- 
agulation or fibrinolytic systems. J Clin Lab Anal. 2003;17(3):77-9. https://doi.org/10.1002/ jcla.10072 PMID: 12696076

7. Hesselvik JF, Blombäck M, Brodin B, Maller R. Coagulation, fibrinolysis, and kallikrein systems in sepsis: relation to outcome. Crit Care Med. 1989;17(8):724-33. https://doi.org/10.1097/00003246-19890800000002 PMID:2502362

8. Lippi G, Bonfanti L, Saccenti C, Cervellin G. Causes of elevated D-dimer in patients admitted to a large urban emergency department. Eur J Intern Med. 2014;25(1):45-8. https://doi. org/10.1016/j.ejim.2013.07.012 PMID:23948628

9. Carr JM, McKinney M, McDonagh J. Diagnosis of disseminated intravascular coagulation. Role of D-dimer. Am J Clin Pathol. 1989; 91(3):280-7. https://doi.org/10.1093/ajcp/91.3.280 PMID:2646905

10. Levi M, Schultz M, van der Poll T. Sepsis and thrombosis. Semin Thromb Hemost. 2013;39(5):559-66. _ https://doi. org/10.1055/s-0033-1343894 PMID:23625756

11. Iskander KN, Osuchowski MF, Stearns-Kurosawa DJ, Kurosawa S, Stepien D, Valentine C et al. Sepsis: Multiple Abnormalities, Heterogeneous Responses, and Evolving Understanding. Physiol Rev. 2013;93(3):1247-88. https://doi. org/10.1152/physrev.00037.2012 PMID:23899564 PMCID:PMC3962548

12. Levi M, Schultz M, van der Poll T. Sepsis and thrombosis. Semin Thromb Hemost. 2013;39(5):559-66. $\quad$ https://doi. org/10.1055/s-0033-1343894

13. PMID:23625756Iskander KN, Osuchowski MF, Stearns-Kurosawa DJ, Kurosawa S, Stepien D, Valentine C et al. Sepsis: Multiple Abnormali- ties, Heterogeneous Responses, and Evolving Understanding. Physiol Rev. 2013;93(3):124788. $\quad$ https://doi.org/10.1152/physrev.00037.2012 PMID:23899564 PMCID:PMC3962548

14. Reitsma PH, Branger J, Van Den Blink B, Weijer S, Van Der Poll T, Meijers JC. Procoagulant protein levels are differentially increased during human endotoxemia. J Thromb Haemost. 2003;1(5):1019-23. https://doi.org/10.1046/ j.1538-7836.2003.00237.x PMID:12871371

15. Kim GY, Park SY, Yoon HJ, Suh JT, Kang SY, Lee WI. Investigation of Hemostatic Changes in Patients with Sepsis. Korean J Lab Med. 2007;27(3):157-61. https://doi.org/10.3343/ kjlm.2007.27.3.157 PMID: $\underline{18094569}$

16. Ersoy B, Nehir H, Altinoz S, Yilmaz O, Dundar PE, Aydogan A. Prognostic Value of Initial Antithrombin Levels in Neonatal Sepsis. Indian Pediatr. 2007;44(8):581-4. PMID:17827633

17. Kinasewitz GT, Yan SB, Basson B, Comp P, Russell JA, Cariou A et al; PROWESS Sepsis Study Group. Universal changes in biomarkers of coagulation and inflammation occur in patients with severe sepsis, regardless of causative micro-organism. Crit Care. 2004;8(2):R82-90. PMCID:PMC420030

18. Mavrommatis AC, Theodoridis T, Economou M, Kotanidou A, El Ali M, ChristopoulouKokkinou $\mathrm{V}$ et al. Activation of the fibrinolytic system and utilization of the coagulation inhibitors in sepsis: comparison with severe sepsis and septic shock. Intensive Care Med. 2001;27(12):1853-9. $\quad$ https://doi.org/10.1007/ s00134-001-1139-8 PMID:11797019

19. Peker E, Akbayram S, Geylani H, Dogan M, Kirimi E. Global Fibrinolytic Capacity in Neonatal Sepsis. Clin Appl Thromb Hemost. 2011;17(6):E64-9. PMID:21078608

\section{How to Cite This Article}

Sharma A, Sikka M, Gomber S, Sharma S. Plasma Fibrinogen and D-dimer in Children With Sepsis: A Single-center Experience. Iranian Journal of Pathology, 2018; 13(2): 272-275. 